\title{
Correction to: Measurement and Control of Charged Particle Beams
}

\section{Correction to:}

M. G. Minty et al., Measurement and Control of Charged

Particle Beams, https://doi.org/10.1007/978-3-662-08581-3

The original version of the book was published in 2003 with exclusive rights reserved by the Publisher. As of November 2019 it has been changed to an open access publication: (c) The Editor(s) (if applicable) and The Author(s) 2003.

The copyright of the individual chapters has therefore changed to: (C) The Author(s) 2003 All chapters in the book are licensed under the terms of the Creative Commons Attribution 4.0 International License.

Any third party material is under the same Creative Commons license as the book unless specified otherwise below. 